\title{
OVER CAPACITY NARAPIDANA DI LEMBAGA PEMASYARAKATAN, FAKTOR PENYEBAB, IMPLIKASI NEGATIF, SERTA SOLUSI DALAM UPAYA OPTIMALISASI PEMBINAAN NARAPIDANA
}

\author{
Angkasa \\ Fakultas Hukum Universitas J enderal Soedirman Purwokerto \\ E-mail: drangkasa_64@yahoo.com
}

\begin{abstract}
Overcapacity happened because growth rate dweller of ill assorted prison with dwelling medium of prison. Besides seems there are some other impeller factors to the happening of the paradigm overcapacity or law factors of itself which tend to oriented institutional crime (prison). Overcapacity tend to to have negative implication to some matters for example the lowering of security storey; level / observation and also the happening of prisonization. Solution of overcapacity convict in prison in the effort optimalization construction of convict in the effort optimalization construction of convict for example with a few actions having the character of non-institutional in the form of conditional crime, probation, suspended, compensation, restitution and also usage of restorative justice.
\end{abstract}

Keyword: overcapacity, convict, justice restorative

\begin{abstract}
Overcapacity terjadi karena laju pertumbuhan penghuni lapas tidak sebanding dengan sarana hunian lapas. Selain itu tampaknya terdapat beberapa faktor pendorong lain untuk terjadinya overcapacity paradigma atau faktor hukumnya itu sendiri yang cenderung berorientasi pada pidana institusional (penjara). Overcapacity cenderung berimplikasi negatif terhadap beberapa hal antara lain rendahnya tingkat pengamanan/ pengawasan serta terjadinya prisonisasi. Solusi overcapacity narapidana dalam Lapas dalam upaya optimalisasi pembinaan narapidana dalam upaya optimalisasi pembinaan narapidana antara lain dengan beberapa tindakan yang bersifat non-institutional berupa pidana bersyarat, probation, pidana yang ditangguhkan, kompensasi, restitusi serta penggunaan restorative justice.
\end{abstract}

Kata kunci: overcapacity, narapidana, restorative justice

\section{Pendahuluan}

Lembaga Pemasyarakatan (Lapas) merupakan institusi dari sub sistem peradilan pidana mempunyai fungsi strategis sebagai pelaksanaan pidana penjara dan sekaligus sebagai tempat bagi pembinaan narapidana sebagaimana diamanatkan dalam Undang-undang no 12 tahun 1995 tentang Pemasyarakatan. Fungsi Lapas ini sesungguhnya sudah sangat berbeda dan jauh lebih baik dibandingkan dengan fungsi penjara jaman dahulu dengan dasar hukum Peraturan Penjara (Gestichten Reglement S.1917 no. 708).
Surat Keputusan Menteri Kehakiman Republik Indonesia No. 02-PK.04.10 Tahun 1990 Tentang Pola Pembinaan narapidana/tahanan, Lapas dalam sistem pemasyaraktan selain sebagai tempat pelaksanaan pidana penjara (kurungan) juga mempunyai beberapa sasaran srategis dalam pembangunan nasional. Tujuan tersebut antara lain dinyatakan bahwa Lapas mempunyai fungsi ganda yakni sebagai lembaga pendidikan dan lembaga pembangunan.

Sebagai lembaga pendidikan, Lapas mendidik napi agar menjadi manusia yang berkualitas, yaitu manusia yang beriman dan bertaqwa kepada Tuhan Yang Maha Esa, berbudi 
pekerti luhur, berkepribadian, mandiri, maju, tangguh, cerdas, kreatif, terampil, berdisiplin, yang memiliki kesadaran beragama, bermasyarakat, berbangsa dan bernegara, memiliki kemampuan intelektual dan berkesadaran hukum. Sebagai lembaga pembangunan, Lapas bertugas membentuk narapidana sebagai manusia pembangunan yang produktif, baik selama di dalam Lapas maupun setelah berada kembali di masyarakat serta ikut mensukseskan pembangunan.

Namun demikian dalam perjalanan waktu tampak jelas bahwa tujuan pembinaan napi ini banyak menghadapi hambatan dan berimplikasi pada kurang optimalnya bahkan dapat menuju pada kegagalan fungsi sebagai lembaga pembinaan. Permasalahan mendasar yang tampak riil adalah adanya kelebihan hunian (overcapacity) narapidana di Lapas-lapas hampir seluruh Indoenasia. Hal ini diungkapkan antara lain oleh mantan Menteri Hukum dan Hak Asasi Manusia Andi Mattalatta, maupun Dirjen Pemasyarakatan Departemen Hukum dan HAM Untung Sugiyono. Hal senada juga dikemukakan oleh beberapa mantan napi seperti halnya Roy Marten maupun Sussongko Suhardjo, amatan Pelaksana Harian Sekretaris Jenderal Komisi Pemilihan Umum ketika menjalani masa pidana penjara.

Berdasarkan penjelasan Andi Mattalata, menyebutkan bahwa pada tahun 2008 penghuni Lapas di seluruh Indonesia mencapai 130.832 orang dengan rincian 54.307 tahanan dan 76.525 napi. J umlah tersebut sangat tidak seimbang dengan kapasitas lapas yang hanya 81.384 orang. Artinya terjadi overcapacity hampir $45 \%^{1}$

Beberapa contoh adanya overcapacity terjadi di Lapas-lapas wilayah Jawa Barat. Lapas Ciamis yang dibangun tahun 1887 itu seharusnya hanya menampung 118 orang, ke-nyataannya, sekitar 335 tahanan dan napi menempati Lapas. Kondisi seperti itu juga terjadi di Lapas Narkoba Kelas IIA Banceuy Bandung, dari kapasitas 402 orang, Lapas Banceuy saat ini dihuni 1.052 napi. Jika dihitung rata-rata, dari

\footnotetext{
1 http:// news. okezone.com
}

22 Lapas dan rutan di Jawa Barat mengalami overcapacity hingga $198 \%$ dengan jumlah napi dan tahanan 15.662 orang. Tingkat hunian ini tergolong dalam daftar Lapas terpadat di Indonesia. ${ }^{2}$ Contoh lain dapat dikemukakan kondisi hunian Lapas Cipinang sebagaimana diungkapkan oleh Roy Marten mantan napi penghuni Lapas tersebut yang menyebut bahwa daya muat 1.200 narapidana nyatanya dipadati lebih dari 4.000 orang. $^{3}$

Fenomena tersebut di atas jelas bukan merupakan faktor kondusif bagi suatu proses pembinaan narapidana yang muaranya mencapai tujuan pemidanaan yantara lain reintegrasi sosial dan dapat kembali diterima oleh masyarakat serta dapan menjalankan perannya sebagai anggota masyarakat seperti anggota masyarakat lainnya. Dalam beberapa politik pemasyarakat bahkan diharapkan selepas kembali hidup di masyarakat akan dapat menjadi manusia pembangunan dengan bekal pembinaan yang diperoleh di di dalam Lapas selama menjalani pidana penjara.

Berkaitan dengan hal tersebut maka beberapa aspek yang berkaitan dengan overcapacity meliputi faktor penyebab, implikasi negatif, serta solusi dalam upaya optimalisasi pembinaan narapidana menjadi penting untuk dibicarakan sebagaimana yang tersaji dalam tulisan ini.

\section{Pembahasan}

\section{Faktor Penyebab Overcapacity Narapidana dalam Lapas}

Overcapacity terjadi karena laju pertumbuhan penghuni lapas tidak sebanding dengan sarana hunian lapas. Prosentase input narapidana baru dengan out put narapidana sangat tidak seimbang, dengan perbandingan input narapidana baru jauh melebihi out put narapidana yang selesai menjalani masa pidana penjaranya dan keluar dari lapas. Beberapa kasus tindak pidana yang menimbulkan banyaknya narapidana baru berkaitan dengan peningkatan yang sangat pesat pada terjadinya tindak pidana

\footnotetext{
http:/ / klipingut. wordpress. com

3 http://gatra.com
} 
khususnya yang berkaitan dengan narkoba, pencurian serta kekerasan terhadap anak.

Selain banyaknya peningkatan pada terjadinya tindak pidana tersebut di atas, tampaknya terdapat beberapa faktor pendo-rong lain untuk terjadinya overcapacity paradigma atau faktor hukumnya itu sendiri. Hukum yang dimaksud di sini utamanya hukum pidana materiil, formil serta hukum pelaksanaan pidana penjara. Sehubungan dengan hal tersbut Patra M Zein sebagai Ketua YLBHI misalnya menyatakan bahwa politik pemidaaan saat ini yang tidak tepat sehingga setiap orang dapat dengan mudah masuk penjara dan menyebab-kan kondisi Lapas overcapacity. Patra juga mendesak pemerintah merevisi Kitab Undang-undang Hukum Pidana (KUHP) dan Kitab Undang-undang Hukum Acara Pidana (KUHAP) yang dinilai sudah tidak relevan dengan kondisi sekarang. ${ }^{4}$

\section{Implikasi Negatif Overcapacity Narapidana dalam Lapas bagi Pembinaan Narapidana}

Overcapacity cenderung berimplikasi negatif terhadap beberapa hal antara lain rendahnya tingkat pengamanan/pengawasan. Dirjen Pemasyarakatan Departemen Hukum dan HAM Untung Sugiyono mencontohkan, jumlah narapidana dan tahanan yang ada mencapai 130.075 orang, sementara petugas keamanan yang tersedia cuma 10.617 orang. Konsekuensinya 1 orang petugas Lapas harus mengawasi 48 orang. Jumlah ini jelas jauh dari kondisi ideal, rasio idealnya 1 banding $25 .{ }^{5}$ Pengamanan yang rendah dapat memicu berbagai masalah antara lain kaburnya napi, banyak terjadi keributan dan tidak terlaksananya proses pembinaan napi sebagaimana yang seharusnya terjadi. Implikasi lain atas lemahnya pengawasan ini berimbas pula pada tingkat kriminalitas di Lapas. Kasus penemuan narkoba dalam razia di Lapas tercatat sebanyak 64 kasus, dengan 96 orang yang terlibat merupakan salah satu contoh konkrit. Catur Sapto Edy selaku Wakil Ketua Komisi III DPR RI juga menyatakan bahwa overcapacity juga menyebabkan kerawanan berupa

\footnotetext{
4 http:// www.rakyatmerdeka.co.id

5 http:// www. detiknews.com
}

kaburnya napi, perkelahian dan transaksi narkoba. ${ }^{6}$

Secara teoritik dapat dijelaskan bahwa overcapacity dapat menimbulkan prisonisasi (prisonization) ${ }^{7}$. Sykes dengan "pains of imprisonment theory" mengatakan bahwa pada hakikatnya prisonisasi terbentuk sebagai respon terhadap masalah-masalah penyesuaian yang dimunculkan sebagai akibat pidana penjara itu sendiri dengan segala bentuk perampasan (deprivation) $^{8}$. Penyesuaian di sini sebagai meredakan rasa sakit terhadap penderitaan sebagai akibat perampasan. ${ }^{9}$ Perampasan di sini adalah hilangnya sesuatu yang biasanya dimiliki dan/atau dinikmati oleh orang-orang yang bebas, sehingga menimbulkan suatu penderitaan termasuk dalam hal ini adalah penderitaan harus berdsesak-desakan di dalam Lapas sebagai akibat dari overcapacity. Pendapat Sykes di dukung oleh Steven Box yang menyatakan bahwa prisonisasi adalah suatu adaptasi yang dilakukan oleh napi terhadap kepedihan atau penderitaan tertentu dalam penjara. ${ }^{10}$

Lebih Ianjut dikatakan oleh Steven Box bahwa pada hakikatnya seorang narapidana yang baru masuk adalah merupakan bagian dari sebuah segitiga. Dalam sudut yang pertama adalah organisasi atau wakil-wakil resmi yaitu norma petugas. Sudut yang kedua berdirilah kelompok-kelompok narapidana yang menawarkan penyelesaian berbagai macam-macam masalah di antaranya mengatasi suatu perampasan yang merupakan penderitaan. ${ }^{11}$

Dengan demikian adaptasi terhadap kepedihan atau penderitaan yang dilakukan oleh

\footnotetext{
6 www.rakyatmerdeka.co.id

7 Prisonisasi atau Prisonization adalah istilah yang diciptakan oleh Donald Clemmer yang dikonsepkan sebagai "The taking on, in greater or lesser degree, of the falkways, more, customs and general culture of the penitentiary" (Stanton Wheeler, "Socialication in Correctiomal Institutions" dalam Sir Leon Radzinowichz and Marvis E Wolfgang (ed), Crime and Justice. New York: Basic Books, Inc. Publishers, tanpa tahun hlm. 194)

8 Loc. cit., hlm. 197.

9 Roger Hood and Richard Sparks, 1978. Key Issues in Criminology. Wiedenfeld and Nicolson, London: World University, hlm. 222.

10 Steven Box, 1981, Deviance, Reality \& Society, Second Edition, Holt. Rinchert and Winston, London, New York, Sudney Toronto, hlm. 216.

11 lbid. hlm. 219-220.
} 
seseorang narapidana pada hakikatnya karena seseorang narapidana yang masuk dalam penjara akan dihadapkan pada dua alternatif. Alternatif pertama adalah masuk atau mengikuti aturan petugas yang berarti mengalami perampasan dengan rasa penderitaan yang kuat. Alternatif kedua adalah masuk dalam budaya masyarakat narapidana yang berarti mengurangi penderitaan atas perampasan yang di alami.

Berkaitan dengan hal tersebut dikatakan oleh Sykes dan Messinger bahwa apabila sekelompok narapidana banyak menuju keadaan antagonis bersama, maka banyak masalah dari kehidupan penjara menjadi lebih akut. Sebaliknya kalau sekelompok narapidana bergerak dalam arak solidaritas, yang dituntut oleh aturan narapidana, rasa sakit di penjara menjadi kurang berat. Suatu masyarakat narapidana yang kohesif membawa narapidana pada suatu kelompk sosial sehingga ia dapat mengenal dirinya sendiri dan akan mendukungnya dalam perjuangan melawan petugas (norma petugas) ${ }^{12}$

Beberapa bentuk prisonisasi antara lain terjadinya perampasan sesama napi, pencurian di dalam kamar napi, perkelahian kelompok, perploncoan khususnya bagi napi yang baru masuk, pengelompokan berdasarkan kedaerahan, bahasa khusus untuk tidak mudah dikenali oleh orang luar, homoseksual serta kode etik untuk saling melindungi rahasia sesama napi. ${ }^{13}$

Prisonisasi ini tampaknya sangat tidak kondusif bagi tujuan pembinaan napi. John Irwin misalnya berpendapat bahwa prisonisasi dapat mempunyai implikasi negatif seperti yang diungkapkan sebagai berikut: "This unique culture produced a social order perculair to the prison and that prisoner become "prisonized" into this culture, which disrupted their reentry into the outside society and sometimes deepened their criminality and anty society". ${ }^{14}$

\footnotetext{
${ }^{12}$ Roger Hood and Richard Sparks, 1978. Key Issues in Criminology, London: World University Library hlm. 222.

${ }^{13}$ Angkasa, 1993, Prisonisasi dan Permasalahannya Terhadap Pembinaan Narapidana (Suatu Studi di Lembaga Pemasyarakatan Semarang dan Lembaga Pemasyarakatan Purwokerto, (Thesis) Pada Program Pascasarjana Bidang IImu Hukum Undip Semarang, hIm. 145

${ }^{14}$ Romli Atmasasmita, 1983, Kepenjaraan Dalam suatu Bunga Rampai. Bandung: Armico. hlm. 48-49.
}

Implikasi negatif dari prisonisasi di atas berakar dari suatu kenyataan dimana sistem sosial narapidana sangat mendukung dan melindungi narapidana yang sangat mendalami pola-pola tingkah laku kriminal dan sebaliknya akan sangat tidak mendukung bahkan menindas atau mengancam narapidana yang masih menunj ukan loyalitas pada dunia non-kriminal. ${ }^{15}$

Berkaitan dengan hal itu pula Romli Atmasasmita menyatakan "... pada diri seorang narapidana selama dalam penjara, jelas bahwa sikap dan nilai-nilai yang dianut seseorang narapidana dalam konteks masyarakat narapidana, akan secara serius menghambat usaha resosialisasi narapidana. ${ }^{16}$ Clemmer juga menyatakan " ... and that men who became completely prisonesed were much more likely to commit further offences after release from prison than men who did not". ${ }^{17}$ Lebih Ianjut Clemmer mencatat dan menggambarkan bahwa kebudayaan dan organisasi sosial dalam penjara yang ia temukan berbentuk suatu sistem, banyak mempunyai karakteristik yang sangat mengganggu terhadap hal-hal yang berkaitan dengan proses rehabilitasi. ${ }^{18)}$

Prisonisasi pada hakikatnya juga mempunyai dampak negatif terutama bagi penjahat kebetulan, pendatang baru di dunia kejahatan. Hal tersebut tercermin dari pernyataan Bernes dan Teeters yang menyatakan bahwa penjara telah tumbuh menjadi tempat pencemaran yang pada hakikatnya justeru oleh penyokongpenyokong penjara dicoba untuk dihindari, sebab di tempat-tempat ini penjahat-penjahat kebetulan (accidental offenders) dirusak melalui pengalaman-pengalamannya dengan penjahat kronis. Bahkan personil yang baikpun telah gagal untuk menghilangkan keburukan yang sangat besar dari penjara ini. ${ }^{19)}$

Pengalaman dengan penjahat kronis di maksudkan pula bahwa terdapat proses saling

\footnotetext{
15 Ibid. hlm. 49.

16 Romli Atmasasmita, 1982, op. cit. hlm. 38.

17 Roger Hood and Richard Sparke, 1978, op. Cit., hlm. 227

18 Stanton Wheeler, op. cit., hlm. 194

19 Muladi \& Barda Nawawi Arief, 1984, Teori-teori dan Kebijakan Pidana. Bandung: Alumni, hlm. 79. Periksa pula: Barnes \& Teeters, 1953. New Horizon in Criminology, Second Edition, New Delhi: Prentice Hall of India, hlm. 813.
} 
belajar anatar napi dalam dunia kejahatan dapat dijelaskan dengan teori dari Edwin Sutherland tentang Differential Association. Teori ini berdasarkan pada proses belajar yaitu bahwa perilaku kejahatan adalah perilaku yang dipelajari.

Menurut Sutherland, perilaku kejahatan adalah perilaku manusia pada umumnya sama dengan perilaku yang bukan kejahatan. Dalam menjelaskan proses terjadinya perilaku kejahatan Sutherland mengajukan 9 proposisi sebagai berikut. Pertama, perilaku kejahatan adalah perilaku yang dipelajari; kedua, perilaku kejahatan dipelajari dalam interaksi dengan orang lain dalam proses komunikasi. Komunikasi tersebut terutama bersifat lesan maupun dengan menggunakan bahasa isyarat; ketiga, bagian yang terpenting dalam proses mempelajari tingkah laku kejahatan terjadi dalam kelompok personal yang intim; keempat, apabila perilaku kejahatan dipelajari, maka yang dipelajari tersebut, meliputi (a). teknik melakukan kejahatan; (b). motif tertentu, dorongan, alasan pembenar dan sikap; kelima, arah tertentu dari motif dan dorongan dipelajari dari batasan atas aturan hukum sebagai yang menguntungkan atau tidak; keenam, seseorang menjadi delinkuen karena berlebihan dalam berhubungan dengan pola tingkah laku jahat daripada yang tidak jahat; ketujuh, Differential Association dapat bervariasi dalam frekuensinya; kedelapan, proses dalam mempelajari perilaku kejahatan melalui hubunganhubungan dengan pola-pola kejahatan dan menyangkut seluruh mekanisme yang dilibatkan pada setiap proses belajar yang lain; dan kesembilan, karena perilaku kejahatan merupakan pernyataan dari kebutuhan-kebutuhan dan nilai-nilai umum, akan tetapi hal tersebut tidak dijelaskan oleh kebutuhan-kebutuhan dan nilainilai umum tersebut sebab perilaku yang bukan kejahatan juga merupakan pernyataan dari nilai-nilai dan kebutuhan yang sama ${ }^{20}$

Berdasarkan hal tersebut maka pergaulan narapidana dengan narapidana yang lain secara

\footnotetext{
${ }^{20}$ George B. Vold Thomas J. Bernard, 1986, Theoritical Criminology, Third Edition, New York: Oxford University Press, hlm. 78.
}

intens tanpa diimbangi dengan kegiatan yang positif berupa pebinaan spiritual dan mental serta keikutsertaan pada program ketrampilan kerja selama menjalani pidana penjara di dalam Lapas, maka seorang narapidana ketika selesai menjalani pidana penjara dan hidup bebas di masyarakat luar bukannya menjadi baik dalam arti berbuat sebagaimana diatur dalam norma yang hidup dalam masyarakat meliputi norma agama, kesusuilaan, kesopanan serta hukum namum cenderung akan mengulangi melakukan tindak pidana lagi. Pada banyak kasus ditemukan bahwa justeru terjadi peningkatan secara kualitatif dan kuntitatif dalam hal tindak pidana yang dilakukan serta hasil yang diperoleh dari tindak pidana yang dilakukan. Modus operandi dalam melakukan tindak pidana mengalami peningkatan yang diperoleh dari hasil pembelajaran dari narapidana yang lain.

Berkaitan dengan hal tersebut konggres PBB ke lima tahun 1975 mengenai "The Prevention of Crime and Treatment of Offenders" dalam salah satu laporannya menyatakan bahwa pengalaman penjara demikian membahayakan sehingga merusak atau menghalangi secara serius kemampuan sipelanggar untuk mulai lagi ke keadaan patuh pada hukum setelah ia dikeluarkan dari penjara. ${ }^{21)}$ Dalam keterkaitan dengan bahaya-bahaya yang ditimbulkan dalam pidana penjara Konggres Kedua PBB mengenai Pencegahan Kejahatan dan Pembinaan Pelanggar hukum pada tahun 1960 di London - berkaitan dengan diterimanya Standard Minimum Rules - telah mengeluarkan rekomendasi untuk membatasi atau mengurangi penggunaan yang luas dari pidana penjara pendek.

\section{Solusi Overcapacity Narapidana dalam Lapas sebagai Upaya Optimalisasi Pembinaan Nara- pidana}

Beberapa kebijakan dalam rangka mengurangi overcapacity tampaknya telah dilakukan oleh pemerintah antara lain dengan pembuatan kamar baru, rehabilitasi bangunan hingga pembangunan Lapas baru yang mem-

\footnotetext{
${ }^{21)}$ Barda Nawawi Arief, 1986. op. cit., hlm. 82-85.
} 
punyai tujuan utama menambah daya tampung napi. Meski demikian upaya tersebut tampaknya tidak signifikan mengatasi overcapacity mengingat penambahan jumlah napi yang masuk masih jauh lebih banyak dibanding penambahan ruangan maupun napi yang keluar. Apalagi pembangunan Lapas baru selain membutuhkan waktu setidaknya 3 tahun juga membutuhkan biaya besar. Secara normatif terdapat kebijakan melalui Peraturan Menteri Dephukham yang tertuang dalam permen Dephukham No.M.2.PK.04-10 Tahun 207 dilakukan penyederhanaan tata pemberian hak-hak napi. Di antaranya penyederhanaan persyaratan pembebasan bersyarat, cuti bersyarat, dan cuti menjelang bebas.

Melalui kebijakan seperti ini tampaknya memang dapat menguragi kepadatan hunian napi di Lapas. Sebagai contoh dikemukakan oleh Kepala Divisi Pemasyarakatn Kanwil Dephukham J awa Barat, Dedi Sutardi yang menyatakan bahwa dengan kebijakan tersebut di harapkan sekitar 5.000 napi di Jawa Barat dapat dibebaskan. Namun demikian langkah tersebut walau di satu sisi dapat mengatasi kepadatan di Lapas namun menjadi dapat dipertanyakan tetang kualitas keluaran Lapas yang berfungsi pula sebagai wadah pembinaan dan juga dari segi keadilan terutama dari perspektif korban. Korban yang melihat napi sebagai eks pelaku kejahatan memperoleh perlakuan istimewa seperti itu dapat melukai rasa keadilannya. ${ }^{22}$

Sehubungan dengan hal tersebut di atas maka tampaknya harus dilakukan upaya lain dalam upaya mengatasi masalah overcapacity narapidana dalam lapas. Beberapa tindakan yang bersifat non-institutional antara lain pidana bersyarat, probation, pidana yang ditangguhkan, kompensasi, restitusi dan sebagainya. ${ }^{23}$ Dalam perkembangan yang terkini melalui model restorative justice tampaknya dapat mengurangi populasi napi dalam Lapas dan aspek keadilan tetap dapat tercapai dengan baik.

\footnotetext{
22 Klipingut.wordpress.com

${ }^{23}$ Muladi, 1985, Lembaga Pidana Bersyarat, Bandung: Alumni, hlm. 151.
}

Beberapa tindakan non-institutional tersebut di atas dapat dijelaskan sebagai berikut. Pertama adalah Pidana bersyarat (voorwaardelijk veroordeling) secara normatif di atur dalam ketentuan Pasal 14 a KUHP sampai Pasal $14 \mathrm{~F}$ KUHP dengan segala peraturan pelaksanaannya. Penjatuhan pidana terhadap terpidana dengan pidana bersyarat menjadikan yang bersangkutan tidak harus menjalani pidana penjara dalam Lapas asalkan memenuhi syaratsyarat tertentu. ${ }^{24} \mathrm{Hal}$ ini mengandung arti pula bahwa pidana bersyarat dapat mengurangi poopulasi nai di Lapas. Muladi mengatakan bahwa ditinjau dari segi masyarakat secara finansiil maka pidana bersyarat yang merupakan pembinaan di luar lembaga akan lebih murah dibandingkan dengan pembinaan di dalam lembaga. ${ }^{25}$ Selain itu Pidana bersyarat dan bentuk-bentuk alternatif pidana perampasan kemerdekaan lain yang hampir sama misalnya probation, antara lain mempunyai keuntungan-keuntungan sebagai berikut: Keuntungan pertama, pidana bersyarat akan memberikan kesempatan kepada terpidana untuk memperbaiki dirinya di masyarakat, sepanjang kesejahteraan terpidana dalam hal ini dipertimbangkan sebagai hal yang lebih utama daripada risiko yang mungkin diderita oleh masyarakat, seandainya si terpidana dilepas di masyarakat. Hal yang sangat penting untuk diperhatikan adalah keharusan untuk menghilangkan kekhawatiran terpidana untuk kemungkinan dimasukkan ke lembaga pemasyarakatan, pada permulaan perencanaan pelaksanaan pidana bersyarat. Dalam rangka pemberian kesempatan ini, persyaratan yang paling utama adalah kesehatan mental dari terpidana.

Keuntungan yang kedua adalah bahwa pidana bersyarat memungkinkan terpidana untuk melanjutkan kebiasaan-kebiasaan hidup-

\footnotetext{
${ }^{24}$ Dalam ketentuan Pasal 14c KUHP ditentukan bahwa di samping syarat umum bahwa terpidana tidak akan melakukan perbuatan pidana, hakim dapat menetapkan syarat khusus bahwa terpidana dlam waktu yang lebih pendek dari masa percobaanya, harus mengganti segala atau sebagian kerugian yang ditimbulkan oleh perbuatan pidananya. Di samping itu dapat pula ditetapkan syarat khusus lainnya mengenai tingkah laku terpidana yang harus dipenuhi selama masa percobaan atau selama sebagian masa percobaannya.

${ }^{25}$ Muladi, 1985, op.cit., hlm. 153-154.
} 
nya sehari-hari sebagai menusia, yang sesuai dengan nilai-nilai yang ada di masyarakat. Kebia-saan-kebisaan ini antara lain adalah melakukan tugas pekerjaannya, melaksanakan kewajiban-kewajibannya di dalam keluarga, ikut serta di dalam kegiatan rekreasi dan tindakantindakan lain yang akan bermanfaat baginya sebagai anggota masyarakat dan sebaliknya hal ini juga sangat bermanfaat bagi masyarakat. Manfaat yang ketiga adalah, bahwa pidana bersyarat akan mencegah terjadinya stigma yang diakibatkan oleh pidana perampasan kemerdekaan, yang oleh Richard D Schwartz dan Jerome H. Skolnick disebut sebagai salah satu konsekuensi di luar hukum yang harus diperhitungkan di dalam kebijaksanaan para penegak hukum. Stigma ini seringkali dirasakan juga oleh keluarganya. Sehubungan dengan hal ini, maka keluarga terpidana tersebut harus memberikan bantuan kepada pelaksana pidana bersyarat dan bantuan ini dapat berupa rasa simpati, dorongan-dorongan positif terhadap terpidana, bantuan-bantuan yang bersifat materiil dan disiplin. ${ }^{26}$

Kedua, adalah tentang Restitusi dalam hal ini dalam perspektif viktimologi. Hakikatnya restitusi berkaitan dengan perbaikan atau restorasi perbaikan atas kerugian fisik, moral mau pun harta benda, kedudukan dan hak-hak korban atas serangan pelaku tindak pidana (penjahat). Restitusi merupakan suatu tindakan restitutif terhadap pelaku tindak pidana yang berkarakter pidana dan menggambarkan suatu tujuan koreksional dalam kasus pidana. ${ }^{27}$

Burt Galaway secara lebih komperhensif menyatakan tentang restitusi sebagai berikut.

Restitution is defined to mean a requirement, either imposed by agents of the criminal justice system, or undertaken voluntary by the wrong-doer but with the consent of the criminal justice system, by which the offender engages is

\footnotetext{
${ }^{26}$ Richard D. Schwartz \& J erome H. Skolnick, The Stigma of "Ex-Con" and the Problem of Reintegration, dalam: Corrections: Problem and Pros-pects, Prentice Hall, Inc., Englewood Cliffs, New J ersey, 1975, hlm. 127.

27 Angkasa, 2004. Kedudukan Korban dalam Sistem Peradilan Pidana (Pendekatan Viktimologis terhadap Korban Tindak Pidana Perkosaan (Disertasi), Semarang: Universitas Diponegoro, hlm. 129.
}

acts designed to make reparation for harm resulting from the criminal offence. The definition has three central components: action by offender which may be either voluntary or coerced, knowledge and consent of the agents of the criminal justice system and the repairing of damages ${ }^{28}$.

Restitusi dalam kaitannya dengan overcapacity, mempunyai manfaat apabila diintegrasikan dengan lembaga pidana bersyarat, implikasinya mengurangi populasi hunian penjara (Lapas) sekaligus penghematan dana pengeluaran pemerintah. Dengan tidak masuknya pelaku menjalani pidana penjara di Lapas maka pemerintah dapat menghemat dana yang seharusnya dikeluarkan untuk memberi makan, perawatan serta pembinaan bagi napi. ${ }^{29}$

Ketiga, adalah pengembangan model penyelesaian kasus pidana yang bermanfaat pula untuk mengurangi populasi napi dalam lapas dengan penyelesaian secara perdamaian antara pelaku dan korban. Dalam hal ini pelaku tidak harus masuk dalam lapas apabila proses perdamaian tercapai. Model ini dikenal dengan restorative justice. Restorative justice is a process whereby all the parties with a stake in a particular offense come together to resolve collectively how to deal with the aftermath of the offense and its implications for the future. $^{30}$

Russ Immarigeon memberikan pengertian restorative justice sebagai berikut.

Restorative justice is a process that brings victims and offenders together to face each other, to inform each other about their crimes and victimization, to

\footnotetext{
${ }^{28}$ J ohn Harding, 1982, Victims and Offenders Needs and Responsibilities. Bedford Square Press|NCVO, hlm.16.

${ }^{29}$ Angkasa, 2004, Op.cit., hlm. 57; Bandingkan dengan hasil studi Lawrence (1990) yang menunjukkan bahwa dari sejumlah 3000 pelaku tindak pidana di Texas selama 7 tahun terakhir, lebih memilih program restitusi daripada program pidana penjara biasa. Program restitusi ini hanya mengeluarkan biaya $\$ 215$, sedangkan program pemenjaraan biayanya sebesar $\$ 750$. Studi lain dari Hudson \& Galaway (1980); Lawrence (1990); Patterson (1978), juga melaporkan bahwa restitusi lebih ekonomis daripada dengan prosedur sistem peradilan pidana biasa. (William G. Doerner, Steven P. Lab, Loc.cit.)

30 Tony Marshall, 1999, Restorative Justice: An Overview. London: Home Office Research Development and Statistics Directorate, hlm. 5.
} 
learn about each others' backgrounds, and to collectively reach agreement on a 'penalty' or ' sanction. ${ }^{131}$

Keuntungan restorative justice antara lain sebagai selain sebagai sarana untuk mengurangi polulasi napi di Lapas, juga lebih mendorong terciptanya reintegrasi sosial pelaku tindak pidana ke dalam kehidupan masyarakat serta mengurangi terjadinya stigma. Hal ini sebagaimana dinyatakan oleh Bazemore sebagai berikut.

Current approaches may be criminogenic in the sense that they isolate and stigmatize the offender, reducing the likelihood of successful reintegration into the law-abiding community. Punishment makes the offender less likely to focus on the victim of the crime than on himself. Familial relationships with the offender are damaged. Restorative sanctions, on the other hand, require accountability. They require the offender to take responsibility for his actions by making right of the wrong that he has inflicted on the victim. At the same time, restorative justice exhorts the community to make every effort to facilitate the successful reintegration into the community. In this way, he argues, restorative justice has the better potential to rehabilitate offenders ${ }^{32}$

\section{Penutup \\ Simpulan}

Berdasarkan pembahasan tersebut di atas maka dapat disimpulkan sebagai berikut. Pertama, overcapacity terjadi karena laju pertumbuhan penghuni lapas tidak sebanding dengan sarana hunian lapas. Selain itu tampaknya terdapat beberapa faktor pendorong lain untuk terjadinya overcapacity paradigma atau faktor hukumnya itu sendiri yang cenderung berorientasi pada pidana institusional (penjara). Kedua, overcapacity cenderung berimplikasi negatif terhadap beberapa hal antara lain

\footnotetext{
${ }^{31}$ Russ Immarigeon, 1999, "The Impact of Restorative J ustice Sanctions on the Lives and Well-Being of Crime Victims: A Review of the International Literature" in Restorative Juvenile Justice: Repairing the Harm of Youth Crime, edited by Gordon Bazemore and Lode Walgrave, Monsey, NY: Criminal J ustice Press, hlm. 306.

32 http:/ / www. restorativejustice. org/ intro/ tutorial-introduction-to-restorativr-justice
}

rendahnya tingkat pengamanan/pengawasan serta terjadinya prisonisasi. Ketiga, solusi overcapacity narapidana dalam Lapas dalam upaya optimalisasi pembinaan narapidana dalam upaya optimalisasi pembinaan narapidana antara lain dengan beberapa tindakan yang bersifat non-institutional berupa pidana bersyarat, probation, pidana yang ditangguhkan, kompensasi, restitusi serta penggunaan restorative justice.

\section{Saran}

Berdasarkan hal tersebut di atas maka untuk dapat mengatasi overcapacity narapidana di dalam lembaga pemasyarakat ataupun rumah tahanan yang cenderung berimplikasi negative pada tujuan pemidanaan atara lain berupa terjadinya prisonosasi dan rawannya sistem pengamanan maka, penyelesaian perkara pidana perlu menggunakan pendekatan baru yakni restorative justice.

\section{DAFTAR PUSTAKA}

Angkasa. 1993. Prisonisasi dan Permasalahannya Terhadap Pembinaan Narapidana (Suatu Studi di Lembaga Pemasyarakatan Semarang dan Lembaga Pemasyarakatan Purwokerto. Semarang: Program Pascasarjana Bidang Ilmu Hukum Undip;

-.---.. 2004. Kedudukan Korban dalam Sistem Peradilan Pidana (Pendekatan Viktimologis terhadap Korban Tindak Pidana Perkosaan (Disertasi). Semarang: Universitas Diponegoro;

Atmasasmita, Romli. 1983. Kepenjaraan Dalam suatu Bunga Rampai. Bandung: Armico;

Barnes and Teeters. 1953. New Horizon in Criminology. Second Edition. New Delhi: Prentice Hall of India;

Box, Steven. 1981. Deviance, Reality \& Society. Second Edition. Holt. Rinchert and Winston. New York: Sudney Toronto;

George, B. Vold Thomas and J. Bernard. 1986. Theoritical Criminology. Third Edition. New York: Oxford University Press;

Harding, John. 1982. Victims and Offenders Needs and Responsibilities. Bedford: Square Press/ NCVO; 
Hood, Roger and Richard Sparks. 1978. Key Issues in Criminology. London: World University Library;

Immarigeon, Russ. 1999. "The Impact of Restorative J ustice Sanctions on the Lives and Well-Being of Crime Victims: A Review of the International Literature" in Restorative Juvenile Justice: Repairing the Harm of Youth Crime. NY: Criminal J ustice Press;

Marshall, Tony. 1999. Restorative Justice: An Overview. London: Home Office Research Development and Statistics Directorate;

Muladi dan Barda Nawawi Arief. 1984. Teoriteori dan Kebijakan Pidana. Bandung: Alumni Radzinowichz, Sir Leon and Marvis E Wolfgang (ed). tanpa tahun. Crime and J ustice. New York: Inc. Publishers;

Muladi, 1985, Lembaga Pidana Bersyarat. Bandung: Alumni;

Schwartz, Richard D. and J erome H. Skolnick, 1975. The Stigma of "Ex-Con" and the Problem of Reintegration. New Jersey: Prentice Hall Inc. Englewood Cliffs. 